\title{
Autour de l'abbé Raynal: genèse et enjeux politiques de l'“Histoire des deux Indes", sous la direction de Antonella ALIMENTO et Gianluigi GOGGI
}

\section{Pierino Gallo}

\section{(2) OpenEdition}

\section{Journals}

\section{Édition électronique}

URL : http://journals.openedition.org/studifrancesi/16409

DOI : 10.4000/studifrancesi. 16409

ISSN : 2427-5856

\section{Éditeur}

Rosenberg \& Sellier

\section{Édition imprimée}

Date de publication : 1 juillet 2019

Pagination : 161

ISSN : 0039-2944

\section{Référence électronique}

Pierino Gallo, «Autour de l'abbé Raynal: genèse et enjeux politiques de I"Histoire des deux Indes", sous la direction de Antonella ALIMENTo et Gianluigi GOGGI », Studi Francesi [En ligne], 187 (LXIII | I) | 2019, mis en ligne le 01 juillet 2019, consulté le 24 janvier 2021. URL : http://journals.openedition.org/studifrancesi/ 16409 ; DOI : https://doi.org/10.4000/studifrancesi.16409

Ce document a été généré automatiquement le 24 janvier 2021.

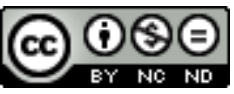

Studi Francesi è distribuita con Licenza Creative Commons Attribuzione - Non commerciale - Non opere derivate 4.0 Internazionale. 


\section{Autour de l'abbé Raynal: genèse et enjeux politiques de l'"Histoire des deux Indes", sous la direction de Antonella ALIMENTO et Gianluigi GOGGI}

Pierino Gallo

\section{RÉFÉRENCE}

Autour de l'abbé Raynal: genèse et enjeux politiques de l'"Histoire des deux Indes", sous la direction de Antonella ALIMENTO et Gianluigi GOGGI, Ferney-Voltaire, 2018, "Centre international d'étude du XVIII ${ }^{\mathrm{e}}$ siècle», $322 \mathrm{pp}$.

1 Réunissant, outre les deux directeurs, seize contributeurs (Kenta Ohji, Koen Stapelbroek, Stéphane Pujol, Gilles Gourbin, Muriel Brot, Marco Platania, Alessandro Tuccillo, Ann Thomson, Daniel Droixhe, Guido Abbattista, Hans-Jürgen Lüsebrink, Didier Kahn, Manuela Albertone, Reinier Salverda, Cecil Patrick Courtney et Anthony Strugnell), ce volume collectif issu d'un colloque organisé à Pise en février 2016 porte, comme son titre l'indique, sur une œuvre phare du siècle des Lumières: l'Histoire des deux Indes. Les textes qui le composent s'inscrivent dans un double programme: reconstruire la genèse de l'Histoire d'une part, examiner les enjeux politiques qui s'y dessinent de l'autre. Conçu dans le contexte culturel de la France après la paix de Paris (1763), l'ouvrage de Raynal devait en effet répondre à un objectif précis: essayer de résoudre la fracture qui s'était produite, vers la moitié du siècle, entre les «philosophes» (qualifiés de «parti») et la monarchie de Louis XV, érigeant une plateforme où les questions politiques et coloniales pouvaient être librement débattues. S'appuyant sur ce constat, les contributions réunies dans ce volume abordent le projet 
de l'abbé d'un triple point de vue: celui du discours sur les empires et le commerce (discours que l'Histoire des deux Indes développe dans un rapport dialectique avec son temps), celui du rôle joué par les colonies dans la construction de l'œuvre et, pour finir, celui des éditions et des collaborateurs. Cette approche, explique Anthony Strugnell, est d'ailleurs suggérée par la nature polyphonique de l'Histoire des deux Indes: «ce qui caractérise l'ouvrage dirigé par Raynal, ce sont ses origines perçues dans les sources imprimées, événementielles, et humaines qui l'ont façonnées, et les ambitions politiques qui l'ont dirigées» (Postface, pp. 301-302). Rédigés par des chercheurs aux compétences diverses, les travaux recueillis par Antonella Alimento et Gianluigi Goggi apportent à ce sujet une pierre du premier ordre, offrant des clés de lecture sans lesquelles notre compréhension de l'œuvre de Raynal resterait excessivement restreinte. Même les lecteurs qui connaissent bien l'abbé pourront en tirer profit. 